(2) OPEN ACCESS

- Additional material is published online only. To view please visit the journal online (http://dx.doi.org/10.1136/ jnnp-2019-322326).

For numbered affiliations see end of article.

\section{Correspondence to}

Stephanie Licata, Biogen Inc, Cambridge, MA, USA; stephanie. licata@biogen.com

Received 24 October 2019 Revised 20 February 2020 Accepted 14 March 2020 Published Online First 31 March 2020

\section{Check for updates}

(C) Author(s) (or their employer(s)) 2020. Re-use permitted under CC BY-NC. No commercial re-use. See rights and permissions. Published by BMJ.

To cite: Butzkueven $\mathrm{H}$ Kappos L, Wiendl H, et al. J Neurol Neurosurg Psychiatry 2020;91:660-668.

\title{
Long-term safety and effectiveness of natalizumab treatment in clinical practice: 10 years of real-world data from the Tysabri Observational Program (TOP)
}

\author{
Helmut Butzkueven, ${ }^{1}$ Ludwig Kappos, ${ }^{2}$ Heinz Wiendl, ${ }^{3}$ Maria Trojano, ${ }^{4}$ Tim Spelman, ${ }^{5,6}$ \\ Ih Chang, ${ }_{1}^{7}$ Rachna Kasliwal, ${ }^{8}$ Seema Jaitly, ${ }^{8}$ Nolan Campbell, ${ }^{9}$ Pei-Ran Ho, ${ }^{9}$ \\ Stephanie Licata, ${ }^{9}$ On behalf of the Tysabri Observational Program (TOP) Investigators
}

\section{ABSTRACT \\ Objective The Tysabri Observational Programme}

(TOP), which began $>10$ years ago, is an open-label, multinational, prospective observational study evaluating the long-term safety and effectiveness of natalizumab in relapsing-remitting multiple sclerosis patients.

Methods These data provide a 10-year interim analysis of safety and effectiveness in TOP. Annualised relapse rates (ARRs) and disability progression/improvement were analysed using the Poisson model and the Kaplan-Meier method, respectively. Analyses included patients on natalizumab and those who discontinued natalizumab but remained in TOP.

Results As of November 2017, TOP included 6148 patients. Overall, 829 patients (13.5\%) experienced $\geq 1$ serious adverse event (SAE), with infection the most common (4.1\%). Fifty-three patients (0.9\%) had confirmed progressive multifocal leukoencephalopathy. SAE data were consistent with natalizumab's known safety profile; no new safety signals were identified. A total of 3210 patients (52.2\%) discontinued natalizumab; 2117 (34.4\%) withdrew from TOP. Median time on natalizumab was 3.3 (range $0-11.6$ ) years; median follow-up time was 5.2 (range 0-10.8) years. The on-natalizumab ARR was 0.15 , a $92.5 \%$ reduction from the year before initiation. Ten-year cumulative probabilities of disability worsening and improvement were $27.8 \%$ and $33.1 \%$, respectively. On-natalizumab ARRs were similar between patients who discontinued or remained on natalizumab, suggesting limited attrition bias.

Conclusions Since the TOP 5-year interim analysis (December 2012), cohort size (6148 vs 4821), median exposure (3.3 vs 1.8 years) and median follow-up time (62 vs 26 months) have increased. This 10-year interim analysis further supports the robust real-world effectiveness and well-established safety profile of natalizumab.

Trial registration number NCT00493298.

\section{INTRODUCTION}

Natalizumab is a highly efficacious therapy for the treatment of relapsing-remitting multiple sclerosis (RRMS), as demonstrated in clinical trials and a number of real-world studies. ${ }^{1-3}$ Data collected during long-term real-world treatment complement and extend results from randomised clinical trials; real-world data also provide clinicians and patients practical benefit-risk information when considering treatment options. The Tysabri Observational Programme (TOP), which began over 10 years ago, is the largest ongoing real-world study of natalizumab-treated patients with RRMS.

TOP collects data on safety and clinical outcomes in patients with RRMS initiating treatment with natalizumab in clinical practice. In the 5 -year interim analysis of TOP, natalizumab treatment was not associated with new safety signals. ${ }^{4}$ The overall relapse rate was reduced significantly and remained low, and disability levels were stabilised and maintained over time. ${ }^{4}$ A separate analysis showed that the probability of disability worsening and transition to disability milestones remained low over approximately 5.5 years in TOP $^{5}$ while epoch analyses of TOP data indicated better outcomes for patients who remained on natalizumab beyond 2 years of treatment compared with those who discontinued in the first 2 years. ${ }^{6}$ Thus, data from TOP have allowed investigators to address questions regarding the efficacy of natalizumab in the real-world clinical setting, with the ultimate goal of improving care for RRMS patients.

The current 10-year interim analysis of TOP extends the previous 5 -year interim analysis with a larger population and longer duration of natalizumab exposure. In addition to reporting on long-term safety and effectiveness data, this study expands on the previous 5-year interim report by addressing the potential attrition bias inherent in long-term observational studies. To assess attrition bias, effectiveness results were evaluated both in the group of patients with long-term natalizumab treatment (patients with $\geq 8$ years of treatment) and in the group of patients who could have potentially received 8 years of natalizumab treatment had they not discontinued natalizumab. An additional analysis of attrition bias evaluated relapse rates during each year of natalizumab treatment in patients who discontinued or stayed on natalizumab beyond that year. Together, these 10-year interim findings from TOP extend our knowledge of the safety and effectiveness profile of long-term natalizumab treatment. 


\section{METHODS}

\section{Patients}

Patients were enrolled from Germany, the Czech Republic, Belgium, Italy, Canada, The Netherlands, Norway, Finland, France, Slovakia, Australia, Great Britain, Greece, Spain, Mexico, Portugal and Argentina. All patients met criteria for natalizumab prescription in their respective countries. The decision to treat with natalizumab was made prior to patient enrolment. The protocol was approved by each centre's independent ethics committee, and all patients provided written informed consent. The study was performed in accordance with the Declaration of Helsinki.

\section{Study design}

TOP is an ongoing, open-label, multinational, multicentre, prospective observational study of patients with RRMS initiating natalizumab in real-world clinical practice settings. Patients enrolled in TOP were required to have a diagnosis of RRMS and to be natalizumab naïve or have received $\leq 3$ doses of natalizumab in their lifetime at the time of enrolment. Details of the TOP study design have previously been published. ${ }^{4}$ This 10 -year interim analysis includes data from study initiation (July 2007) through 1 November 2017.

\section{Endpoint and assessments}

Demographic and clinical characteristics were recorded at enrolment. Additional assessments took place at regularly scheduled clinical practice visits, which occurred approximately every 6 months. Data on safety and relapses could also be collected at unscheduled visits to evaluate new or worsening neurological symptoms. Data collection was performed using a web-based electronic case report form. Patients who discontinued natalizumab were encouraged to remain in the study. If patients withdrew from the study for any reason, physicians were asked to collect data on any serious adverse events (SAEs) for an additional 6 months where possible.

The primary endpoint was long-term safety (the incidence and pattern of SAEs) in patients receiving natalizumab. SAEs that occurred $\leq 6$ months after the last natalizumab infusion were included, except for progressive multifocal leukoencephalopathy (PML) and death, which were included when they occurred at any time after the first dose of natalizumab. The relationship of each SAE to natalizumab treatment was determined by the reporting physician. Incidence rates of SAEs of interest (opportunistic infections, malignancy and PML) were examined per 1000 patient-years overall as well as during two time intervals ( $\leq 3$ years and $>3$ years), reflecting the median natalizumab treatment duration, to determine if incidence changed over time.

Secondary endpoints evaluated multiple sclerosis (MS) disease activity as measured by relapses and changes in disability. A clinical relapse was defined as new or recurrent neurological symptoms not associated with fever lasting for $\geq 24$ hours and followed by 30 days of stability or improvement. Relapses were recorded up to 84 days after the last dose of natalizumab. New or recurrent neurological symptoms that occurred $<30$ days after the onset of a protocol-defined relapse were considered part of the same relapse. The occurrence and description of relapses, including details on relapses requiring the use of steroids or hospitalisation, were recorded by the prescribing clinician at regular clinical practice visits. Confirmed disability worsening was defined as an increase, confirmed 24 weeks later, of $\geq 0.5$ point from a baseline Expanded Disability Status Scale (EDSS) score of $\geq 6.0, \geq 1.0$ point from a baseline EDSS score of $\geq 1.0$ to $<6.0$ or $\geq 1.5$ points from a baseline EDSS score of 0.0 . Confirmed disability improvement was defined as a decrease of $\geq 1.0$ point from baseline score, confirmed 24 weeks later, among patients with baseline EDSS scores $\geq 2.0$. $^{7}$ Confirmation of 24-week worsening or improvement could occur up to 84 days after the last dose of natalizumab.

\section{Statistical analysis}

Baseline characteristics of TOP patients were summarised using descriptive statistics. Populations in the safety and effectiveness analyses included patients who had provided informed consent, met study inclusion criteria and received $\geq 1$ dose of natalizumab. On natalizumab, annualised relapse rates (ARRs) were analysed using a Poisson model with robust error variance. Analyses of relapse data in patients who did and did not discontinue natalizumab treatment were performed to detect possible attrition bias. Cumulative probabilities of first relapse, disability worsening and disability improvement were estimated using the Kaplan-Meier method. Median EDSS scores over time (based on observed values) stratified by baseline EDSS score category were also analysed.

Associations between baseline factors and on-treatment ARRs were evaluated using a negative binomial model. Baseline variables included in an adjusted negative binomial model were age $(\leq 40$ or $>40)$, the number of relapses in the year prior to natalizumab initiation $(\leq 1$ or $>1)$, EDSS score $(\leq 3.0$ or $>3.0)$ and the number of prior disease-modifying therapies (DMTs $(0$, 1 or $\geq 2)$ ). Associations between baseline factors and ARRs in the year prior to enrolment were similarly evaluated to assess pretreatment differences.

\section{RESULTS}

\section{Patient enrolment and baseline characteristics}

As of 1 November 2017, 6148 patients from 17 countries were enrolled in TOP. Baseline characteristics are summarised in table 1 . In the overall population, the median disease duration at baseline was 7.8 years (range $0-48$ years), and 3245 patients $(52.8 \%)$ had EDSS scores $>3.0$. Most patients $(84.5 \%)$ had used another DMT prior to starting natalizumab. Anti-JC virus (JCV) antibody status was tested at enrolment in 4339 of 6148 patients $(70.6 \%)$. A total of 2102 patients $(34.2 \%)$ were anti-JCV antibody positive and 2230 (36.3\%) were anti-JCV antibody negative.

Baseline characteristics are presented not only for the overall population, which includes all patients who enrolled at any time point, but also for patients who had received $\geq 8$ years of natalizumab treatment at the time of the data cut (the $\geq 8$-year treatment cohort) and patients who enrolled $>8$ years prior to the data cut but who discontinued natalizumab before completing 8 years of treatment (the $<8$-year treatment cohort). Characteristics were generally similar between the three groups; however, patients in the $\geq 8$-year treatment cohort appeared to have had a slightly earlier disease course, as evidenced by lower age, disease duration, EDSS score and prior DMT use duration than those in the $<8$-year treatment cohort. In addition, the proportion of patients who were anti-JCV antibody negative at baseline appeared to be greater in the $\geq 8$-year treatment cohort $(59.9 \%)$ than in the overall population $(36.3 \%)$ or the $<8$-year treatment cohort $(13.8 \%)$.

Patient enrolment and disposition data are shown in figure 1. Median time on natalizumab was 3.3 (range 0-11.6) years. Median follow-up time was 5.2 (range $0-10.8$ ) years. As of 1 November 2017, 3210 patients (52.2\%) had discontinued 


\begin{tabular}{|c|c|c|c|}
\hline Characteristic & $\begin{array}{l}\text { Overall } \\
\text { population } \\
(n=6148)\end{array}$ & $\begin{array}{l}\geq 8 \text {-year } \\
\text { treatment } \\
\text { cohort } \\
(n=491) \\
\end{array}$ & $\begin{array}{l}<8 \text {-year } \\
\text { treatment } \\
\text { cohort } \\
(n=1056) \\
\end{array}$ \\
\hline $\begin{array}{l}\text { Age at baseline, mean }(S D) \text {, } \\
\text { years }\end{array}$ & $37.1(9.8)$ & $35.9(9.2)$ & $38.7(9.8)$ \\
\hline Female, n (\%) & $4430(72.1)$ & $366(74.5)$ & $755(71.5)$ \\
\hline \multicolumn{4}{|l|}{$\begin{array}{l}\text { Relapses in year prior to } \\
\text { natalizumab initiation }\end{array}$} \\
\hline Mean (SD) & $2.0(1.0)$ & $2.0(1.1)$ & $2.0(1.1)$ \\
\hline \multicolumn{4}{|l|}{$n(\%)$} \\
\hline$\leq 1$ & $2094(34.1)$ & $164(33.4)$ & $395(37.4)$ \\
\hline$>1$ & $4054(65.9)$ & $327(66.6)$ & $661(62.6)$ \\
\hline \multicolumn{4}{|l|}{ Baseline EDSS score } \\
\hline Mean (SD) & $3.5(1.6)$ & $3.3(1.5)$ & $3.8(1.8)$ \\
\hline$\leq 3.0, \mathrm{n}(\%)$ & $2843(46.2)$ & $240(48.9)$ & $423(40.1)$ \\
\hline$>3.0, \mathrm{n}(\%)$ & $3245(52.8)$ & $250(50.9)$ & $625(59.2)$ \\
\hline Unknown, n (\%) & $60(1.0)$ & $1(0.2)$ & $8(0.8)$ \\
\hline $\begin{array}{l}\text { Disease duration at baseline, } \\
\text { median (range), years }\end{array}$ & 7.8 (0 to 48$)$ & 7.6 (0 to 39$)$ & 8.8 (0 to 48$)$ \\
\hline \multicolumn{4}{|l|}{$\begin{array}{l}\text { Treatment duration prior to } \\
\text { natalizumab initiation, years }\end{array}$} \\
\hline Mean (SD) & $4.0(3.9)$ & $3.8(3.5)$ & $3.8(3.5)$ \\
\hline Median (range) & 2.9 (0 to 22$)$ & 2.7 (0 to 16$)$ & $2.8(0$ to 17$)$ \\
\hline \multicolumn{4}{|l|}{ Prior DMTs, n (\%) } \\
\hline 0 & $952(15.5)$ & 65 (13.2) & $152(14.4)$ \\
\hline 1 & 2897 (47.1) & $241(49.1)$ & $514(48.7)$ \\
\hline$\geq 2$ & 2299 (37.4) & $185(37.7)$ & $390(36.9)$ \\
\hline \multicolumn{4}{|l|}{ Prior MS DMT used, $\mathrm{n}(\%)^{*}$} \\
\hline $\begin{array}{l}\text { Interferon beta-1a } \\
\text { formulations }\end{array}$ & $4494(73.1)$ & $378(77.0)$ & $811(76.8)$ \\
\hline Glatiramer acetate & $2034(33.1)$ & $154(31.4)$ & $322(30.5)$ \\
\hline Fingolimod & $233(3.8)$ & $1(0.2)$ & $3(0.3)$ \\
\hline Dimethyl fumarate & $44(0.7)$ & $0(0)$ & $2(0.2)$ \\
\hline Teriflunomide & $25(0.4)$ & $1(0.2)$ & $1(0.1)$ \\
\hline Alemtuzumab & $2(<0.1)$ & $1(0.2)$ & $0(0)$ \\
\hline $\begin{array}{l}\text { Prior immunosuppressant use, } \\
\mathrm{n}(\%)\end{array}$ & $983(16.0)$ & $82(16.7)$ & $175(16.6)$ \\
\hline $\begin{array}{l}\text { Natalizumab doses prior to } \\
\text { enrolment, mean (SD) }\end{array}$ & $1.1(1.1)$ & $1.2(1.2)$ & $1.2(1.2)$ \\
\hline $\begin{array}{l}\text { Patients who were anti-JCV } \\
\text { antibody positive, } \mathrm{n}(\%)\end{array}$ & $2102(34.2) \dagger$ & $170(34.6) \dagger$ & $293(27.7) \dagger$ \\
\hline $\begin{array}{l}\text { Patients who were anti-JCV } \\
\text { antibody negative, } \mathrm{n}(\%)\end{array}$ & $2230(36.3) \dagger$ & $294(59.9) \dagger$ & $146(13.8) \dagger$ \\
\hline
\end{tabular}

*Patients may have used $>1$ DMT.

tAnti-JCV antibody status at enrolment was tested in 4339 patients in the overall population, 469 patients in the $\geq 8$-year treatment cohort and 440 patients in the $<8$-year treatment cohort.

DMT, disease-modifying therapy; EDSS, Expanded Disability Status Scale; JCV, JC virus; MS, multiple sclerosis.

natalizumab and 2117 (34.4\%) had withdrawn from TOP. Of the patients who discontinued natalizumab treatment, 1093 (34.0\%) remained in TOP. The most common reasons for treatment discontinuation were positive anti-JCV antibody serostatus (1487 of 3210 patients $(46.3 \%)$ ), patient decision (831 of 3210 patients $(25.9 \%)$ ) and medication change (616 of 3210 patients (19.2\%)). Among patients who discontinued natalizumab treatment, rates of discontinuation due to reported insufficient efficacy were low and not markedly different between patient cohorts $(12.8 \%$ in the overall population and $13.7 \%$ in the $<8$-year treatment cohort). The most common reasons for withdrawal from TOP were other (543 of 2117 (25.6\%)), patient decision (454 of $2117(21.4 \%)$ ) and lost to follow-up (326 of 2117 (15.4\%)).

At enrolment, 2102 patients (34.2\%) were anti-JCV antibody positive and $2230(36.3 \%)$ were anti-JCV antibody negative. Anti-JCV antibody serostatus was not tested at enrolment in 1809 patients $(29.4 \%)$ and serostatus was missing from seven patients who were tested at enrolment $(0.1 \%)$. Of the 2230 subjects who were anti-JCV antibody negative at enrolment, 565 (25.3\%) had a change of serostatus to positive on treatment. In the 2230 known baseline anti-JCV antibody negative patients, there was a total of 9963.27 person-years of exposure, with an incidence of $5.7 \%$ per person-year.

\section{Safety}

Overall, 829 of 6148 patients (13.5\%) experienced $\geq 1$ SAE and 290 patients (4.7\%) experienced $\geq 1$ SAE considered related or possibly related to natalizumab treatment. Table 2 lists SAEs by System Organ Class and Medical Dictionary for Regulatory Activities preferred terms for SAEs that occurred in $>5$ patients. The most common SAEs were infections and infestations, with an incidence of $4.1 \%$; PML, pneumonia, urinary tract infection and herpes zoster were the most commonly reported infections (table 2). Of note, the rates of development of malignancies and opportunistic infections, with the exception of PML, remained very low.

Opportunistic infections were classified based on the presence of an identifiable organism as well as clinical symptoms. Eleven patients $(0.2 \%)$ had 14 events defined as opportunistic infections other than PML, including herpes zoster, meningitis herpes, encephalitis, herpes simplex encephalitis, herpes zoster disseminated, listeria meningitis (sepsis), pneumonia and pulmonary Mycobacterium kansasii infection (see online supplementary etable 1). The median time to onset for opportunistic infections was 14 months from natalizumab initiation, with a range of 3 months to 5 years. Three patients had two events each: one with pneumonia and staphylococcal sepsis; one with tuberculosis and M. kansasii; and one with listeria sepsis (meningitis) and listeria meningitis (sepsis). Herpes zoster was reported by three patients, herpes meningitis was reported in two patients and the other infections were reported in one patient each. The events were of viral aetiology in eight patients and were bacterial in three patients. Eight cases were referred to the central nervous system (CNS) and three were referred to non-CNS sites.

In the entire cohort, 53 patients $(0.9 \%)$ had confirmed PML. PML patients received a median of 42 doses or months of exposure (range 11-124); 36 of 53 PML cases (67.9\%) occurred in patients receiving natalizumab for $>3$ years. The overall PML incidence rate per 1000 patient-years was 2.034 (95\% CI 1.554 to 2.662). Prior immunosuppressant use was reported by 14 PML patients (26.4\%). Of the $36 \mathrm{PML}$ cases with reported anti-JCV antibody serostatus available 6 months prior to PML development, 35 (97.2\%) were confirmed positive. Within the PML cohort, there were two identified cases of JCV-associated granule cell neuropathy. As of 1 November 2017, 44 of 53 patients diagnosed with PML (83.0\%) were alive.

Overall, there were 66 patients (1.1\%) with 39 types of malignancies. The median time to onset for malignancy was 65 months, with a range of 2 months to 8 years. Of the reported malignancies, four were fatal (lung neoplasm, adenocarcinoma of colon, choroid melanoma and metastatic breast cancer). Breast cancer was the most common malignancy, affecting 19 patients (including invasive ductal breast carcinoma in five 


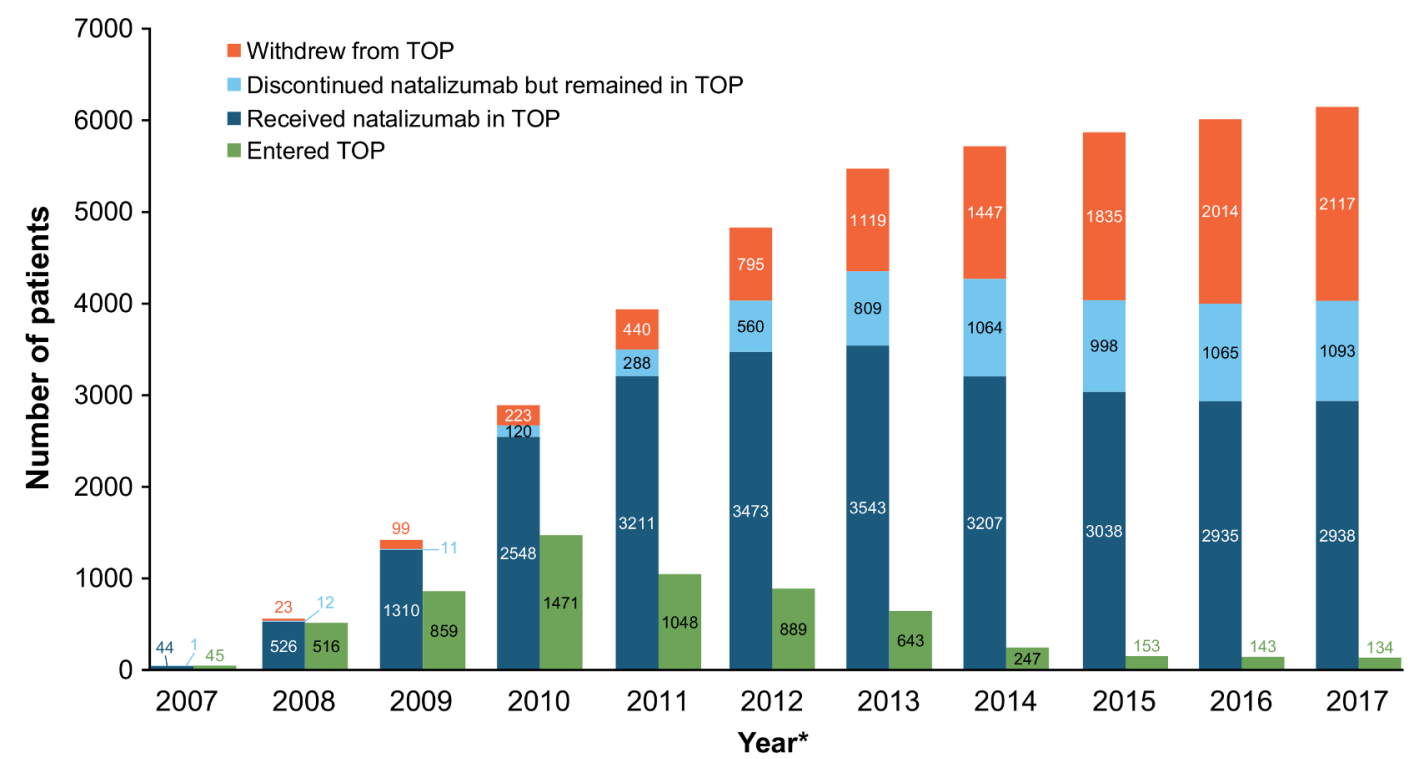

Figure 1 Annual accounting of patients in TOP. Patients who entered TOP in a given year are shown in green, whereas the other categories are combined to indicate the cumulative number of patients in TOP. Patients who received natalizumab in TOP and continued natalizumab treatment through 1 November of that year are shown in dark blue. Patients who discontinued natalizumab but remained in TOP through 1 November of that year are shown in light blue. Cumulative numbers of patients who withdrew over the study duration are shown in orange. *Accounting is shown for study start (July 2007) through 1 November 2017. For all years, patients enrolled after 1 November are accounted for in the following year. TOP, Tysabri Observational Programme.

patients and metastatic breast cancer in two patients). The rate of breast cancer was 86.7 per 100000 patient-years, with a $95 \%$ CI of 52.2 to 135.4 per 100000 patient-years, encompassing the rates of 123.8 per 100000 patient-years in the Surveillance, Epidemiology and End Results (SEER) database ${ }^{8}$ and 80.3 per 100000 person-years in the Global Cancer Incidence, Mortality and Prevalence (GLOBOCAN database). ${ }^{9}$ Other reported malignancies included papillary thyroid cancer in four patients, colon cancer in four patients, renal cancer in three patients and chronic lymphocytic leukaemia in three patients. CNS tumours (one glioblastoma and one oligodendroglioma) were diagnosed in two patients. The remaining malignancies were each diagnosed in $\leq 2$ patients (see online supplementary etable 2 ).

Incidence rates of SAEs of interest (opportunistic infections, PML and malignancy) were evaluated during two time epochs of natalizumab use ( $\leq 3$ years and $>3$ years) to account for the impact of prolonged exposure to natalizumab (table 3). Overall, incidence rates per 1000 patient-years for all three SAEs were relatively low, and $\leq 1.02 \%$ of patients reported these SAEs. When evaluating by time epoch, opportunistic infection incidence rates were higher during the first 3 years of natalizumab treatment than during later natalizumab treatment. Incidence rates appeared to increase slightly for malignancy during the later epoch, though the CIs for both time epochs overlapped. PML incidence rates were approximately three times higher in the second time epoch than in the first.

Other safety events included SAEs related to hypersensitivity reactions ( $n=40$, representing $0.7 \%$ of patients), with four cases reported as anaphylactic reaction, three cases as anaphylactoid reaction, five cases as anaphylactic shock and the remaining 28 cases as hypersensitivity. Just over half of the cases (21 of 40 $(53 \%))$ occurred within the first three doses. Hypersensitivity led to treatment discontinuation in 36 patients and there were no associated fatalities. Two cases were considered unrelated to natalizumab: in one case, the anaphylactic reaction was attributed to another drug and in the other case, the anaphylactic shock was attributed to nut ingestion.
Twelve hepatic events (representing $0.2 \%$ of patients) were reported during the study. All were serious except for one unrelated case of abnormal hepatic function, which remained unresolved even though treatment was discontinued. These hepatic events comprised four cases of drug-induced liver injury (two of which were related to natalizumab), two cases of autoimmune hepatitis and single cases of acute hepatic failure, hepatitis, hepatitis fulminant and liver injury. Median time to onset of hepatic events was 7.6 months, with a range of 1 to 10 months, and natalizumab was discontinued in all cases.

There were 30 deaths $(0.5 \%)$ during the study. The reporting physician classified the deaths as treatment related in eight of these cases: four cases of PML, two cases of immune reconstitution inflammatory syndrome (one of which was combined with MS relapse) and one case each of metastatic breast cancer and autonomic nervous system imbalance.

\section{Effectiveness}

Relapses

During the 10 years of follow-up, the on-natalizumab ARR was 0.15 (95\% CI 0.14 to 0.15 ), a $92.5 \%$ reduction from the ARR of 1.99 (95\% CI 1.97 to 2.02 ) in the year prior to starting natalizumab. Patients had large reductions in on-natalizumab ARR regardless of age category at baseline, baseline EDSS score category or the number of DMTs used prior to natalizumab initiation (see online supplementary etable 3 ). However, patients with a lower baseline EDSS score ( $\leq 3.0$ vs $>3.0$ ), fewer prior DMTs ( 0 vs $1 ; 0$ vs $\geq 2 ; 1$ vs $\geq 2$ ) or fewer relapses in the year prior to treatment ( $\leq 1 \mathrm{vs}>1$ ) had significantly lower on-natalizumab ARRs (online supplementary etable 3 ). The cumulative probability of remaining relapse free at 10 years was $45.8 \%$.

In the overall population, the ARR decreased from 1.99 at baseline to 0.24 at 1 year of natalizumab treatment, and ARRs remained $\leq 0.20$ from 2 to 10 years (figure 2 ). Similar results were observed for the other cohorts: the ARR decreased from 2.04 to 0.21 in the $\geq 8$-year treatment cohort and from 1.97 to 


\begin{tabular}{|c|c|}
\hline Event, $\mathbf{n}(\%)$ & $n=6148$ \\
\hline Patients with $\geq 1$ SAE & $829(13.5)$ \\
\hline \multicolumn{2}{|l|}{ SAEs by SOC and MedDRA preferred term reported in $>5$ patients* } \\
\hline Infections and infestations & $254(4.1)$ \\
\hline PML, confirmed & $53(0.9)$ \\
\hline Pneumonia & $23(0.4)$ \\
\hline Urinary tract infection & $20(0.3)$ \\
\hline Herpes zoster & $17(0.3)$ \\
\hline Escherichia urinary tract infection & $12(0.2)$ \\
\hline Pyelonephritis & $10(0.2)$ \\
\hline Appendicitis & $8(0.1)$ \\
\hline Diverticulitis & $6(0.1)$ \\
\hline Gastroenteritis & $6(0.1)$ \\
\hline Sepsis & $6(0.1)$ \\
\hline Nervous system $†$ & $142(2.3)$ \\
\hline Epilepsy & $18(0.3)$ \\
\hline MS & $15(0.2)$ \\
\hline Syncope & $8(0.1)$ \\
\hline Headache & $7(0.1)$ \\
\hline Sciatica & $6(0.1)$ \\
\hline Uhthoff's phenomenon & $6(0.1)$ \\
\hline Immune system disorders & $92(1.5)$ \\
\hline Immune reconstitution inflammatory syndromeł & $54(0.9)$ \\
\hline Hypersensitivity & $26(0.4)$ \\
\hline $\begin{array}{l}\text { Neoplasms benign, malignant and unspecified (including cysts and } \\
\text { polyps) }\end{array}$ & $88(1.4)$ \\
\hline Breast cancer & $12(0.2)$ \\
\hline Uterine leiomyoma & $9(0.1)$ \\
\hline Injury, poisoning and procedural complications & $75(1.2)$ \\
\hline Fall & $19(0.3)$ \\
\hline Psychiatric disorders & $69(1.1)$ \\
\hline Depression & $18(0.3)$ \\
\hline Suicide attempt & $11(0.2)$ \\
\hline Completed suicide & $7(0.1)$ \\
\hline Pregnancy, puerperium and perinatal conditions & $55(0.9)$ \\
\hline Abortion spontaneous & $37(0.6)$ \\
\hline Musculoskeletal and connective tissue disorders & $48(0.8)$ \\
\hline Intervertebral disc protrusion & $12(0.2)$ \\
\hline Back pain & $8(0.1)$ \\
\hline Surgical and medical procedures & $37(0.6)$ \\
\hline Caesarean section & $8(0.1)$ \\
\hline General disorders and administration site conditions & $32(0.5)$ \\
\hline Fever & $6(0.1)$ \\
\hline Respiratory, thoracic and mediastinal disorders & $26(0.4)$ \\
\hline Pulmonary embolism & $10(0.2)$ \\
\hline Hepatobiliary disorders & $24(0.4)$ \\
\hline Cholelithiasis & $7(0.1)$ \\
\hline Vascular disorders & $19(0.3)$ \\
\hline Deep vein thrombosis & $6(0.1)$ \\
\hline
\end{tabular}

*Each patient was counted only once within each preferred term.

tMS relapse was also reported as an SAE in 20 patients (0.3\%).

$\ddagger$ One case of immune reconstitution inflammatory syndrome was not associated with PML.

MedDRA, Medical Dictionary for Regulatory Activities; MS, multiple sclerosis; PML, progressive multifocal leukoencephalopathy; SAE, serious adverse event; $S O C$, system organ class; TOP, Tysabri Observational Programme.

0.26 in the $<8$-year treatment cohort. For both cohorts, ARRs remained $\leq 0.21$ in subsequent years. In comparisons of ARR between patients who continued natalizumab or discontinued natalizumab in the following year, ARRs were generally similar, and the on-natalizumab ARR of both groups remained $<0.15$ (see online supplementary efigure 1 ).

\section{Disability}

At 10 years, the cumulative probability of 24-week confirmed disability worsening was $27.8 \%$ (figure $3 \mathrm{~A}$ ). At 10 years, the cumulative probability of 24-week confirmed disability improvement was $33.1 \%$ (figure 3B). Of the 5179 patients with baseline EDSS scores $\geq 2.0,1210(23.4 \%)$ experienced a confirmed disability improvement event.

Box plots of EDSS score changes for each year of natalizumab treatment showed that EDSS scores were stable over the 10 years of follow-up (figure 4). When stratified by baseline EDSS score category, patients in each group had mean EDSS score changes of $<1.0$ from baseline over 10 years (see online supplementary efigure 2). At 8 years, the distribution of change in EDSS from baseline in the $\geq 8$-year treatment cohort indicated similarly small change for the majority of patients (see online supplementary efigure 3 ).

\section{DISCUSSION}

This TOP 10-year interim analysis reports on the long-term safety and effectiveness of natalizumab in the largest ongoing real-world study of natalizumab-treated RRMS patients. As of November 2017, 6148 patients were enrolled in TOP, and they had been exposed to natalizumab for a median of 3.3 (range $0-11.6)$ years. Safety findings were consistent with the current safety profile of natalizumab, and no new safety concerns were identified. $^{2} 410$ Natalizumab-treated patients exhibited significant disease control over the course of the study, as evidenced by on-natalizumab ARRs that were reduced and remained low and EDSS scores that remained stable over 10 years.

Over the course of natalizumab treatment, $>85 \%$ of patients had no SAEs. In those patients who did experience an SAE, infection was the most reported SAE, occurring in $4.1 \%$ of patients. Opportunistic infections other than PML were reported in a very small proportion of patients $(0.2 \%)$, which is consistent with the rate of $<1 \%$ observed in clinical trials. ${ }^{10}$ Low incidence rates were also observed for malignancy $(1.1 \%)$; breast cancer was the most common neoplasm $(n=19)$ and occurred at a rate $(86.7$ per 100000 patient-years) lower than the expected European agestandardised incidence rate $(94.2 \text { per } 100000)^{11}$ and in line with the background rates reported by SEER ${ }^{8}$ and GLOBOCAN. ${ }^{9}$

The incidence of PML in TOP was 8.6 cases per 1000 patients overall and 2.0 per 1000 patient-years of natalizumab exposure. Of the 53 confirmed cases, $36(67.9 \%)$ occurred in patients receiving natalizumab for $>3$ years and 14 (26.4\%) occurred in patients reporting prior immunosuppressant use. Of the 36 cases with reported anti-JCV antibody serostatus 6 months prior to PML development, 35 were positive. While previous exposure to JCV is a requirement for PML development, the assay measures only current presence of antibodies to JCV, is limited to seroconversion occurring from last JCV testing to PML development and has an estimated false-negative rate of $2.2 \%{ }^{12}$ These results are in line with the current understanding of the risk factors for PML (duration of treatment, prior immunosuppressant use and the presence of anti-JCV antibodies). ${ }^{13} 14$ The published estimated annualised incidence of PML ranges from 0.0001 ( 0.1 cases/1000 patients) in anti-JCV antibody negative patients to 0.008 (8 cases/1000 patients) in anti-JCV antibodypositive patients with prior immunosuppressant use and 49-60 months of natalizumab exposure. ${ }^{15}$ It should be noted that there 
Table 3 Incidence of opportunistic infection, malignancy and PML during the first 3 years of natalizumab treatment, after 3 years of natalizumab treatment and across the entire treatment period

\begin{tabular}{|c|c|c|c|}
\hline Event & $\leq 3$ years $(n=6148)$ & $>3$ years $(n=3719)$ & Overall $(n=6148)$ \\
\hline Patient-years of follow-up* & 15773.19 & 10233.77 & 26060.25 \\
\hline \multicolumn{4}{|l|}{ Opportunistic infection } \\
\hline Patients with an event, n (\%) & $10(0.16)$ & $1(0.03)$ & $11(0.18)$ \\
\hline Incidence rate $(95 \% \mathrm{Cl}) \dagger$ & 0.634 (0.341 to 1.178$)$ & 0.098 (0.014 to 0.694$)$ & $\begin{array}{l}0.422(0.234 \text { to } \\
0.762)\end{array}$ \\
\hline \multicolumn{4}{|l|}{ PML } \\
\hline Patients with an event, $\mathrm{n}(\%)$ & $17(0.28)$ & $36(0.97)$ & $53(0.86)$ \\
\hline Incidence rate per 1000 patient-years $(95 \% \mathrm{Cl}) \dagger$ & $1.078(0.67$ to 1.734$)$ & $3.518(2.537$ to 4.877$)$ & $\begin{array}{l}2.034(1.554 \text { to } \\
2.662)\end{array}$ \\
\hline \multicolumn{4}{|l|}{ Malignancy } \\
\hline Patients with an event, $\mathrm{n}(\%)$ & $35(0.57)$ & $28(0.75)$ & $63(1.02)$ \\
\hline Incidence rate $(95 \% \mathrm{Cl}) \dagger$ & $2.219(1.593$ to 3.090$)$ & 2.736 (1.889 to 3.963$)$ & $\begin{array}{l}2.417(1.889 \text { to } \\
3.095)\end{array}$ \\
\hline
\end{tabular}

Serious adverse event timing is determined based on event start date. Patients with $>1$ event are counted only once.

*Based on the time from the first dose of natalizumab until the last natalizumab dosing date +6 months.

†Calculated as (1000 $\times$ number of patients with an event) / (total patient-years of follow-up). Exact Cls are calculated based on the Poisson distribution.

$\mathrm{PML}$, progressive multifocal leukoencephalopathy.

are few data on PML rates beyond 6 years of treatment in the postmarketing setting.

Epoch analyses of opportunistic infection, PML and malignancy support an impact of extended exposure on the incidence of these safety events. Over 10 years in TOP, there was a slight increase in malignancy and PML as expected due to age-related increases in cancer risk ${ }^{16}$ and the impact of longer treatment duration on PML risk. ${ }^{13}{ }^{14}$ However, the incidence of opportunistic infections remained low over time, and such infections tended to occur within the first few years of treatment.
Substantial improvements in ARR were seen within the first year of natalizumab treatment, and ARR remained low over the duration of follow-up. Notably, comparable results were observed in the cohorts that received $\geq 8$ years and $<8$ years of natalizumab treatment; yearly relapse rates in patients who discontinued in the following year and those who remained on treatment were similar; and lack of efficacy was rarely given as the reason for natalizumab discontinuation. This analysis of attrition bias is limited by the small number of patients in the $<8$-year treatment group, which decreased from 1056 at

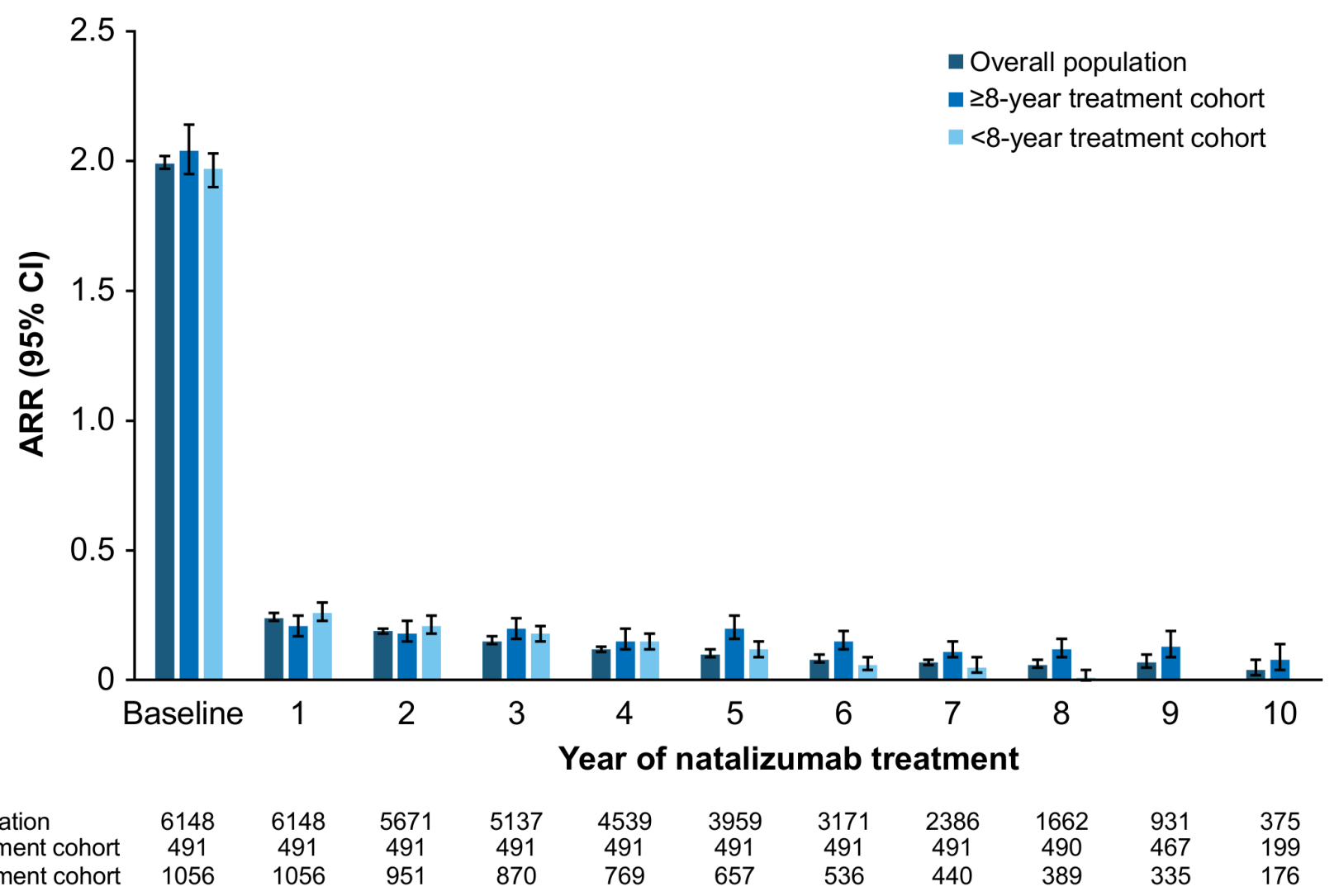

$\mathrm{n}=$

\begin{tabular}{|c|c|c|c|c|c|c|c|c|c|c|c|}
\hline $\begin{array}{l}\text { Overall population } \\
\geq 8 \text {-year treatment cohort }\end{array}$ & $\begin{array}{c}6148 \\
491\end{array}$ & $\begin{array}{c}6148 \\
491\end{array}$ & $\begin{array}{c}5671 \\
491\end{array}$ & $\begin{array}{c}5137 \\
491\end{array}$ & $\begin{array}{c}4539 \\
491\end{array}$ & $\begin{array}{c}3959 \\
491\end{array}$ & $\begin{array}{c}3171 \\
491\end{array}$ & $\begin{array}{c}2386 \\
491\end{array}$ & $\begin{array}{c}1662 \\
490\end{array}$ & $\begin{array}{l}931 \\
467\end{array}$ & $\begin{array}{l}375 \\
199\end{array}$ \\
\hline$<8$-year treatment cohort & 1056 & 1056 & 951 & 870 & 769 & 657 & 536 & 440 & 389 & 335 & 176 \\
\hline
\end{tabular}

Figure 2 Annualised relapse rate (ARR) during each year of natalizumab treatment. 
A.

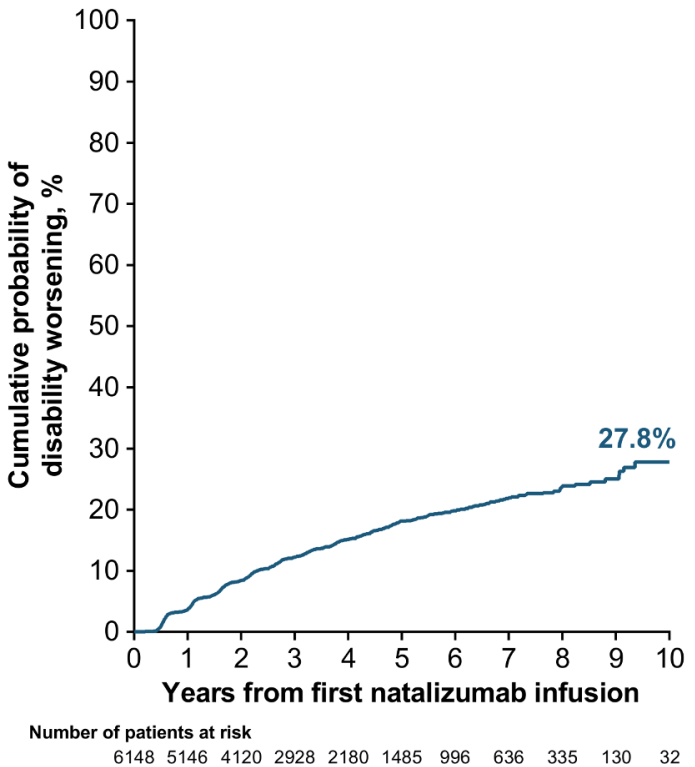

B.

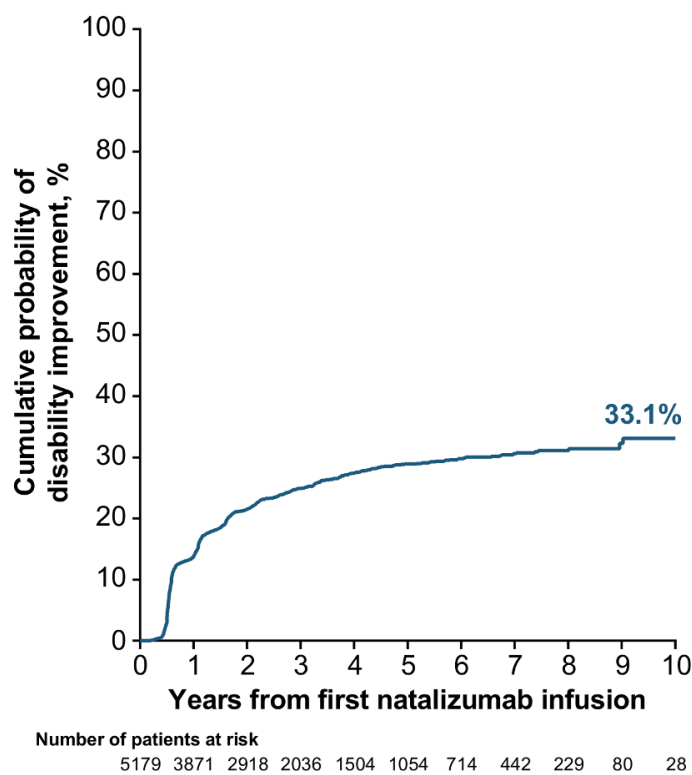

Figure 3 Estimated cumulative probability of 24-week confirmed (A) disability worsening and (B) disability improvement over 10 years in participants with EDSS $\geq 2.0$ at baseline. EDSS, Expanded Disability Status Scale.

baseline to 389 at 8 years. Collectively, however, these data suggest that in TOP, the practice of discontinuing patients with worse efficacy outcomes is limited and therefore attrition bias is unlikely to account for the observed long-term efficacy results.

After initiation of natalizumab, ARR decreased markedly regardless of baseline characteristics such as disease activity or prior DMT use. However, patients earlier in the disease course at baseline, as indicated by lower baseline EDSS score and less prior DMT use, showed significantly lower on-natalizumab ARRs. Similarly, in the TOP 5-year interim analysis, patients with lower EDSS at baseline and less prior DMT use had lower on-natalizumab relapse rates. ${ }^{4}$ These results from TOP underscore the high efficacy of natalizumab in all populations with RRMS.
This 10-year interim analysis of TOP extends the previous analysis ${ }^{4}$ with a larger population (6148 vs 4821 patients), a longer natalizumab exposure duration (median 3.3 vs 1.8 years) and a longer follow-up time (median 62 vs 26 months). Furthermore, TOP is unique in its duration; it includes nearly 500 patients treated with natalizumab for $\geq 8$ years and has recently been extended for a further 5 years in 2019. TOP generates valuable prospective, real-world outcome information on the risks and benefits of long-term natalizumab treatment. The results demonstrate excellent long-term safety and substantial disease control. Long-term treatment was associated with a very low risk of non-PML opportunistic infection and cancer rates similar to those expected in the general population. The planned continued

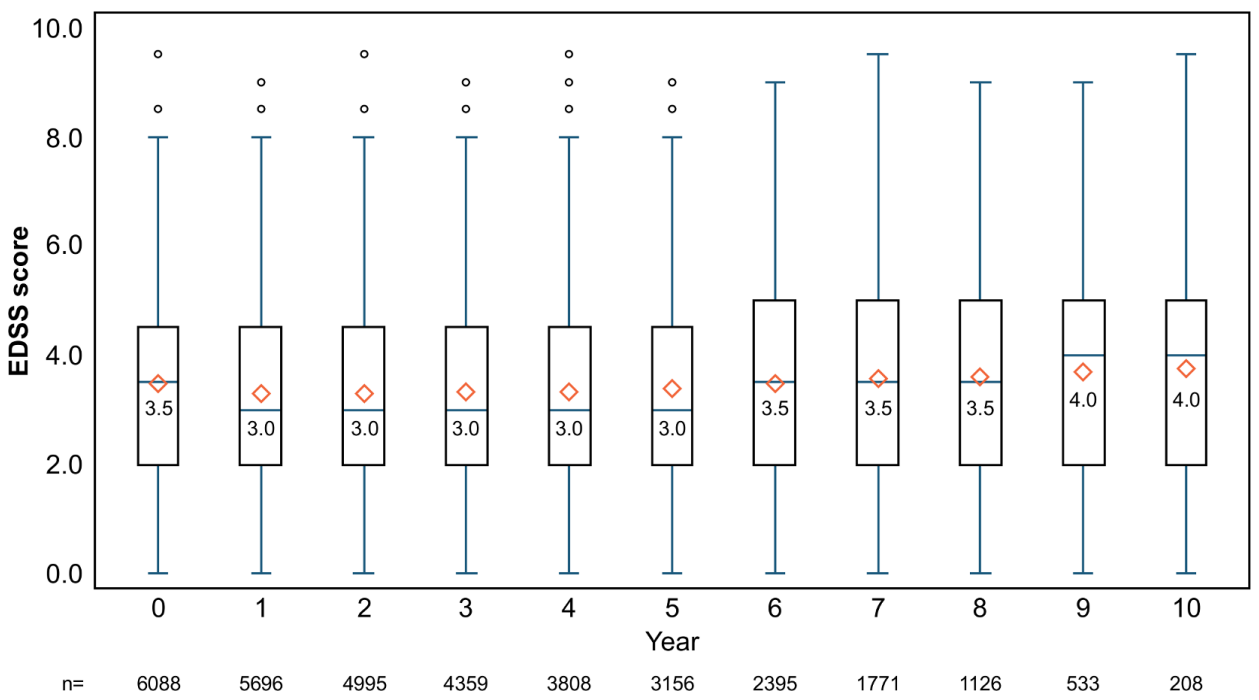

Figure 4 Box plot of Expanded Disability Status Scale (EDSS) scores from enrolment to year 10 in the overall population. The bottom and top edges of the box represent the interquartile range (IQR). The line inside the box represents the median value, which is also indicated by the number. The diamond inside the box indicates the mean value. The whiskers of the box are drawn from the box to the most extreme point that is $\leq 1.5 \times I Q R$. Circles above the whiskers indicate outliers. 
follow-up of TOP patients for up to 15 years will provide further data on real-world outcomes in natalizumab-treated patients.

\section{Author affiliations}

'Department of Neuroscience, Central Clinical School, Alfred Campus, Monash University, Melbourne, Victoria, Australia

${ }^{2}$ Neurologic Clinic and Policlinic, Departments of Medicine, Clinical Research, Biomedicine and Biomedical Engineering, University Hospital and University of Basel, Basel, Switzerland

${ }^{3}$ Department of Neurology, University of Münster, Münster, Germany

${ }^{4}$ Department of Basic Medical Science, Neuroscience and Sense Organs, University of Bari, Bari, Italy

Department of Medicine and Melbourne Brain Centre at the Royal Melbourne Hospital, University of Melbourne, Melbourne, Victoria, Australia

${ }^{6}$ Department of Clinical Neuroscience, Karolinska Institute, Stockholm, Sweden ${ }^{7}$ Biostatistics, Biogen, Cambridge, Massachusetts, USA

${ }^{8}$ Safety and Benefit Risk, Biogen, Cambridge, Massachusetts, USA (at the time of these analyses)

${ }^{9} \mathrm{Global}$ Medical, Biogen, Cambridge, Massachusetts, USA

Acknowledgements The authors would like to acknowledge the TOP study coinvestigators for their ongoing efforts and contributions. The authors would also like to acknowledge Xiaoyu Jiang and Vineeth Kurnala of Biogen for their expert assistance with statistical analysis and interpretation. Alexandra D'Agostino, PhD, of Ashfield Healthcare Communications wrote the first draft of the manuscript based on input from authors, and Joshua Safran of Ashfield Healthcare Communications copyedited and styled the manuscript per journal requirements.

Collaborators Site investigators who participated in data collection: Roby Abraham, Jana Adamkova, Laura Airas, Orhan Aktas, Holger Albrecht, Roger Alsassa, Amaya Alvarez de Arcaya Esquide, Klemens Angstwurm, Olivier Anne, Kerstin Anvari, Julia Aram, Sari Atula, Regine Augspach-Hofmann, Michael Barnett, Bruno Barroso, Emmanuel Barthomolé, Jordi Batlle Nadal, Antonios Bayas, Arnfin Bergmann, Ralf Berkenfeld, Achim Berthele, Antonio Bertolotto, Christophe Billy, Andreas Bitsch, Kin-Arno Bohr, Johannes Böhringer, Jean Paul Borsotti, M. Bos, Olivier Bouquiaux, Hélène Bourteel, Thomas Brosch, Bernhard Buehler, Michel Bureau, Philippe Busson, Helmut Butzkueven, Jo Caekebeke, Carmen Calles Hernández, Ana Belén Caminero Rodríguez, Alejandro Caride, Tamara Castillo Triviño, Cris Constantinescu, Jorge Correale, José Manuel Costa Guerra, Roeland Crols, Miquel D’Haeseleer, Koen de Gans, Maria de Jesus Jimeez, Ma de la Luz Villalpando, Adinda De Pauw, Danny Decoo, Sophie Delalande, Olivier Delerue, Valérie Delvaux, Olivier Dereeper, Norma H. Deri, Olivier Deryck, Richard Devy, Marie D’Hooghe, Sylke Domke, Benedicte Dubois, Martin Duddy, Michal Dufek, Emeline Duhin, Michel Dupuis, Philippe Eck, Hans-Thomas Eder, Astrid Edland, Sven Ehrlich, Eli Skromne Eisenberg, WolfgangGerhard Elias, Evelyn Erdmann, Michael Ernst, Rocio Márquez Estudillo, Juergen Faiss, Guy Fanjaud, Elisabeth Farbu, Jean Marc Faucheux, Jiri Fiedler, Jesús Alfredo Flores Ciro, Francisco Gerardo Flores Ramirez, Jose de Jesus Flores Rivera, Ciro Florio, Benedikt Frank, Claudio Gasperini, Karine Geens, Klaus Gehring, Sohrab Mostoufizadeh Ghalamfarsa, Pierric Giraud, Etienne Godet, Antonio Gonzalez Guardado, Jens Gössling, François Grand'Maison, Thomas Gratz, Orla Gray, Luigi Grimaldi, Christoph Grothe, Daniel Guillaume, Stefan Günther, Carmen Gurau Vasilescu, Kersten Guthke, Judith Haas, Lutz Harms, Timothy Harrower, Päivi Hartikainen, Patrick Hautecoeur, Eva Havrdova, Kerstin Hellwig, G.J.D. Hengstman, Mieke Hermans, Birgit Herting, Suzanne Hodgkinson, Olaf Hoffmann, Roelfien Ida Hogenesch, Tone Hognestad, Markus Horn, Rolf Horn, R.M.M. Hupperts, Rosy N'gbo N'gbo Ikazabo, Olivier Ille, Teis Barclay Ingvaldsen, Samir Ismail, Francois Jacques, Joachim Jaeger, Draga Jichici, Maria José Sá, Waldemar Kafke, Boris Kallmann, Iveta Kastnerová, Ulrich Kausch, Jean Bertin N. Kendjuo, Allan Kermode, John King, Michael Kirsch, Matthias Kittlitz, Chris Kneebone, Karl Christian Knop, Keijo Koivisto, Reinhard Krug, Borries Kukowski, Arnaud Kwiatkowski, Harald Landefeld, Michael Lang, Thomas Lange, Jean-Marc Larrieu, Christoph Lassek, Guy Laureys, Jeannette Lechner-Scott, Leonardo Llamas López, Christian Lund, Richard Macdonell, Gregg MacLean, Alain Maertens de Noordhout, Marcel Maillet Vioud, Carolina Mainella, Rolf Malessa, Imad Malkoun, Renato Mantegazza, Paul Marchetti, Jan Mares, Gisela Martin Ozaeta, Sergio Martínez-Yélamos, María Eugenia Marzo Sola, Said Masri, Uwe Mauz, R. Medaer, Annick Melin, Eva Meluzinová, Christian Menges, Marc Merienne, Sven Meuth, Rune Midgard, Enrico Millefiorini, Daniel Molitor, J.W.B. Moll, Armando Morganho, Antoine Moulignier, Kjell Morten Myhr, Christian Neudert, Richard Nicholas, Chantal Nifle, Alena Novotna, Francis Odeh, Basile Ondze, Michael Osei-Bonsu, Massimo Pandolfo, Katelijne Peeters, Ines Peglau, Domingo Pérez Ruiz, llaria Pesci, Oliver Pfeffer, Maria Pia Amato, Christopher Pilz, Chris Plummer, Udo Polzer, Andre Pouliquen, Sandra Quiñones Aguilar, Lluis Ramio i Torrenta, Cristina Ramo, Sebastian Rauer, lan Redmond, Elisabeth Rehkopf, Gerd Reifschneider, José Rente, Cecile Retif, Nils Richter, Kerstin Roch, Roland Roth, Mariarosa Rottoli, Oliver Ruhnke, Klemens Ruprecht, Michael Sailer, Noel Saines, Rosilda Santos Montero, Serena Scarel, Elio Scarpini, Jürgen Schierenbeck, Sebastian Schimrigk, Eugen Schlegel, Sylke Schlemilch-Paschen, Stephan Schmidt, Frank
Schmitz, Peter Scholz, Michael Schroeter, Ivo Schuetze, Stephan Schüler, Matthias Schwab, Angélique Schyns-Soeterboek, Pierrette Seeldrayers, Nicolas Seiller, François Sellal, Juha Matti Seppä, Melad Shawush, Arno Siever, L.G.F. Sinnige, Ondrej Skoda, Charlotte Smetcoren, Diana Soares, Tiago Souto, Magdalena Stankiewicz, Ivana Stetkarova, Helmut Stienker-Fisse, Klara Stolarikova, Pavel Stourac, Hubert Stratmann, Sergio Sauri Suárez, Manuel Suceveanu, Björn Tackenberg, Jean Philippe Thenint, Oliver Tiedge, Maria Trojano, Hayrettin Tumani, Maritta Ukkonen, Etienne Urbain, Marie-Sylvie Artaud Uriot, Melanie Ursell, Marta Vachova, Martin Valis, Anneke Van Der Walt, Caspar van Munster, Vincent Van Pesch, Wilma Van Steenbergen, Bart Van Wijmeersch, Patrick Vanderdonckt, Erwin Vanroose, W.I.M. Verhagen, François Viallet, Bert Wagner, Marc Wagner, Ronald Wersching, Stephan Wiehler, Brigitte Wildemann, Barbara Willekens, Christina Willems, Martin Wilson, Jörg Windsheimer, Olga Zapletalová, Uwe Ziebold, François Ziegler

Contributors HB contributed to the study design, patient recruitment, data collection, analysis and interpretation of data, and drafting and revising of the manuscript; he takes full responsibility for the finished article and for access to any data and controlled the decision to publish. LK and HW contributed to the study design, analysis and interpretation of data, and drafting and revising of the manuscript. MT contributed to the study design, patient recruitment, data collection, analysis and interpretation of data, and drafting and revising of the manuscript. TS contributed to the analysis and interpretation of data, and drafting and revising of the manuscript. IC, RK and SJ contributed to the statistical analysis, analysis and interpretation of data, and drafting and revising of the manuscript. NC, P-RH and SL contributed to the analysis and interpretation of data, and drafting and revising of the manuscript.

Funding This study was supported by Biogen. Biogen also provided funding for medical writing support in development of this manuscript. Biogen reviewed the manuscript and provided feedback to the authors. The authors provided their final approval of all content.

Competing interests HB has received compensation for steering committee, advisory board and consultancy fees from Biogen, Merck, Roche, Novartis, Oxford Pharmagenesis and Teva and research support from Biogen, Merck, Novartis, MS Research Australia, NHMRC Australia and the UK MS Trust. LK's institution (University Hospital Basel) has received the following in the last 3 years and used exclusively for research support at the department: steering committee, advisory board and consultancy fees from Actelion, Alkermes, Almirall, Bayer, Biogen, Celgene/ Receptos, df-mp, Excemed, GeNeuro SA, Genzyme, Japan Tobacco, Merck, Minoryx, Mitsubishi Pharma, Novartis, Roche, Sanofi, Santhera, Teva and Vianex, as well as royalties for Neurostatus-UHB products; the Research of the MS Centre in Basel has been supported by grants from Bayer, Biogen, Novartis, the European Union, the Roche Research Foundations, the Swiss MS Society and the Swiss National Research Foundation. HW has received honoraria from AbbVie, Actelion, Alexion, Biogen, Cognomed, Evgen, F. Hoffmann-La Roche, MedDay, Merck Serono, Novartis, Roche Pharma AG, Sanofi Genzyme and Teva and research support from Biogen, GlaxoSmithKline GmbH, Roche Pharma AG and Sanofi Genzyme. MT has received compensation for consulting from Biogen, Merck Serono and Novartis; speaker honoraria from Biogen, Merck Serono, Novartis, Sanofi and Teva; and research grants from Biogen, Merck Serono and Novartis. TS has received honoraria for consultancy and funding for travel from Biogen and Novartis. IC, NC, P-RH and SL are employees of and may hold stock and/or stock options in Biogen. RK and SJ were employees of Biogen at the time of these analyses and may hold stock and/or stock options in Biogen.

Patient consent for publication Obtained.

Ethics approval The study was approved by ethics committees for all participating study centres.

Provenance and peer review Not commissioned; externally peer reviewed.

Data availability statement The datasets generated and/or analysed during the current study are not publicly available. The authors and company are fully supportive of allowing independent assessment and verification of these results. Requests for de-identified data should be made via the established company data-sharing policies and processes as detailed on the website http://clinicalresearch.biogen.com/.

Open access This is an open access article distributed in accordance with the Creative Commons Attribution Non Commercial (CC BY-NC 4.0) license, which permits others to distribute, remix, adapt, build upon this work non-commercially, and license their derivative works on different terms, provided the original work is properly cited, appropriate credit is given, any changes made indicated, and the use is non-commercial. See: http://creativecommons.org/licenses/by-nc/4.0/.

\section{REFERENCES}

1 Tysabri (natalizumab) [summary of product characteristics] 2018.

2 Polman $\mathrm{CH}, \mathrm{O}^{\prime}$ Connor PW, Havrdova $\mathrm{E}$, et al. A randomized, placebo-controlled trial of natalizumab for relapsing multiple sclerosis. N Engl J Med 2006;354:899-910. 
3 van Pesch V, Sindic CJ, Fernández O. Effectiveness and safety of natalizumab in real-world clinical practice: review of observational studies. Clin Neurol Neurosurg 2016;149:55-63.

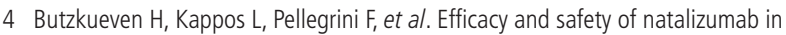
multiple sclerosis: interim observational programme results. J Neurol Neurosurg Psychiatry 2014;85:1190-7.

5 Trojano M, Butzkueven H, Kappos L, et al. Natalizumab treatment shows low cumulative probabilities of confirmed disability worsening to EDSS milestones in the long-term setting. Mult Scler Relat Disord 2018;24:11-19.

6 Wiendl H, Butzkueven H, Kappos L, et al. Epoch analysis of on-treatment disability progression events over time in the Tysabri Observational Program (TOP). PLoS One 2016;11:e0144834.

7 Phillips JT, Giovannoni G, Lublin FD, et al. Sustained improvement in Expanded Disability Status Scale as a new efficacy measure of neurological change in multiple sclerosis: treatment effects with natalizumab in patients with relapsing multiple sclerosis. Mult Scler 2011;17:970-9.

8 Howlader N, Chen VW, Ries LAG, et al. Overview of breast cancer collaborative stage data items - their definitions, quality, usage, and clinical implications: a review of SEER data for 2004-2010. Cancer 2014;120:3771-80
9 Ferlay J, Soerjomataram I, Ervik M.GLOBOCAN 2012 Cancer Incidence and Mortality Worldwide: IARC Cancerbase No. 11. Lyon, France International Agency for Research on Cancer; 2013.

10 . Tysabri (natalizumab) [prescribing information]. Cambridge, MA. Biogen; 2018.

11 Ferlay J, Steliarova-Foucher E, Lortet-Tieulent J, et al. Cancer incidence and mortality patterns in Europe: estimates for 40 countries in 2012. Eur J Cancer 2013;49:1374-403.

12 Lee P, Plavina T, Castro A, et al. A second-generation ELISA (STRATIFY JCVTM DxSelect ${ }^{T M}$ ) for detection of JC virus antibodies in human serum and plasma to support progressive multifocal leukoencephalopathy risk stratification. J Clin Virol 2013;57:141-6.

13 Bloomgren G, Richman S, Hotermans C, et al. Risk of natalizumab-associated progressive multifocal leukoencephalopathy. N Eng/ J Med 2012;366:1870-80.

14 Ho P-R, Koendgen H, Campbell N, et al. Risk of natalizumab-associated progressive multifocal leukoencephalopathy in patients with multiple sclerosis: a retrospective analysis of data from four clinical studies. Lancet Neurol 2017;16:925-33.

15 Physician information and management guidelines for multiple sclerosis patients on TYSABRI therapy. Version 17, 2017. Available: http://medicinesauthority.gov.mt/file. aspx?f=3565 [Accessed 1 Mar 2019].

16 Aunan JR, Cho WC, Søreide K. The biology of aging and cancer: a brief overview of shared and divergent molecular hallmarks. Aging Dis 2017;8:628-42. 